\title{
MORPHOMETRIC STUDY OF THE BONY ORBIT
}

\author{
Sruthi ${ }^{1}$, Biju Urumese Palatty2, Geetha S. G
}

14th Year MBBS Student, Amrita School of Medicine, Amrita Vishwa Vidyapeetham, Kochi, Kerala, India.

${ }^{2}$ Associate Professor, Department of Anatomy, Amrita School of Medicine, Amrita Vishwa Vidyapeetham, Kochi, Kerala, India.

${ }_{3}^{3}$ Assistant Professor, Department of Anatomy, Amrita School of Medicine, Amrita Vishwa Vidyapeetham, Kochi, Kerala, India.

\section{ABSTRACT}

\section{BACKGROUND}

Ocular surgeries and craniofacial surgeries require retrobulbar nerve blocks to produce anaesthesia and akinesia of the eyeball, which involves a risk to the optic nerve.

The aim of this study is to determine the distance of the optic canal from various bony landmarks on the orbital margin of both sides of the skull and correlate these values with the orbital index.

\section{MATERIALS AND METHODS}

For the study, 62 human dry skulls of unknown sex were obtained from the bone bank of Anatomy Department, AIMS, Kochi. Using a digital Vernier calliper, the following parameters were measured: orbital height, orbital width, distance of the optic canal from certain landmarks on the orbital margins (Superior, Inferior, Medial and Lateral). The orbital index was calculated.

Statistical Analysis- The observations were analysed using paired t-test ( $\mathrm{p}<0.05$ was considered to be significant). The statistical software used was IBM SPSS version 20.0.

Settings and Design- Anatomy Department, AIMS, Kochi. This is a descriptive study.

\section{RESULTS}

The mean distance between the optic canal and the landmarks on the superior, inferior and medial margins is significantly different on right and left sides (significance, $p=0.001$ ). Whereas, the mean distance of the optic canal from a point on the zygomaticofrontal suture (lateral margin) did not show any significant difference on both sides. The mean values of the orbital index on the left and right sides were 79.48 and 80.40 respectively and not significantly different $(p=0.517) .67 .7 \%$ of the total skulls observed belonged to microseme category (orbital index $\leq 83$ ). The safe distance to the optic nerve from the orbital margins were obtained by reducing $5 \mathrm{~mm}$ from the shortest distance on each side.

\section{CONCLUSION}

The knowledge of these values is vital in the evaluation, diagnosis, pre-operative and per-operative planning of management for craniofacial syndromes, post-traumatic facial deformities and in the treatment of orbital abnormalities to produce the best aesthetic and functional result. It is also of relevance to anaesthetists in ocular surgeries, while various nerve blocks are being employed.

\section{KEY WORDS}

Orbital Index, Optic Canal Orbital Margin, Safe Distance to Optic Nerve.

HOW TO CITE THIS ARTICLE: Sruthi S, Palatty BU, Geetha SG. Morphometric study of the bony orbit. J. Evolution Med. Dent. Sci. 2018;7(26):3028-3031, DOI: 10.14260/jemds/2018/680

\section{BACKGROUND}

The bony orbits are skeletal cavities located on either side of the nose. The orbital wall apart from protecting the eye from an injury provides points of attachments for six extraocular muscles. This will help in the accurate positioning of the visual axis and to determine the relationship between the eyes, which in turn is essential for the conjugate movements of the eye and the binocular vision.

The orbital roof is formed by the frontal bone and the lesser wing of the sphenoid.

'Financial or Other Competing Interest': None.

Submission 11-05-2018, Peer Review 09-06-2018,

Acceptance 15-06-2018, Published 25-06-2018.

Corresponding Author:

Dr. Geetha S. G,

Assistant Professor

Department of Anatomy,

Amrita School of Medicine,

Amrita Vishwa Vidyapeetham,

Kochi, Kerala, India.

E-mail: geethajkalister@gmail.com

DOI: $10.14260 /$ jemds $/ 2018 / 680$

\section{(c) (i) $(\Theta$}

The optic canal which lies between the roots of the lesser wing is medially bound by the body of the sphenoid. It transmits the optic nerve its meningeal sheath and the ophthalmic artery. Medial wall is formed by lamina papyracea of the ethmoid bone. The orbital floor is mostly made up of the orbital plate of the maxilla, which articulates with the zygomatic bone anterolaterally and the orbital process of the palatine bone posteromedially. The lateral wall is formed by the orbital surface of the greater wing of the sphenoid posteriorly and the frontal process of zygomatic bone anteriorly.

Superior Orbital Fissure (SOF) is the gap between the greater and the lesser wings of the sphenoid bone. The SOF connects the cranial cavity with the orbit and transmits the oculomotor, trochlear and abducens nerves, branches of the ophthalmic nerve and the ophthalmic vein.[1]

The orbital margin consists of four curved sides. The supraorbital margin is notched or canalised near the medial end for the passage of the supraorbital nerve and artery. The lateral margin is formed by the conjoined processes of the frontal and zygomatic bone. The infraorbital margin is 
formed by the zygomatic bone and the maxilla. The medial margin of the orbit consists of two ridges, which overlap. Inferiorly, the anterior lacrimal crest of the frontal process of maxilla and superiorly the posterior lacrimal crest of the lacrimal bone.

The knowledge of these values is vital in the evaluation, diagnosis, pre-operative and per-operative planning in the management of craniofacial syndromes, post-traumatic facial deformities and orbital abnormalities to produce the best aesthetic and functional result. It is also of relevance to anaesthetists in ocular surgeries, while various nerve blocks are being employed.

\section{Study Design}

Descriptive study.

\section{Objective}

Aim of the present study was to determine the orbital index and the distance of the optic canal from various landmarks on the orbital margin on both sides of the skull and to correlate the values so obtained with the orbital index. The safe distance to the optic nerve from the orbital margin on both sides of the skull was also measured.

\section{MATERIALS AND METHODS}

62 human dry skulls of unknown sex were obtained for the study from the bone bank of Anatomy Department, AIMS, Kochi. The skulls with damaged orbital margins and walls were excluded. Using a digital Vernier calliper, the following measurements were taken-

1. Orbital height- the maximum vertical diameter of the orbital margin.

2. Orbital width- the maximum transverse diameter of the orbital margin.

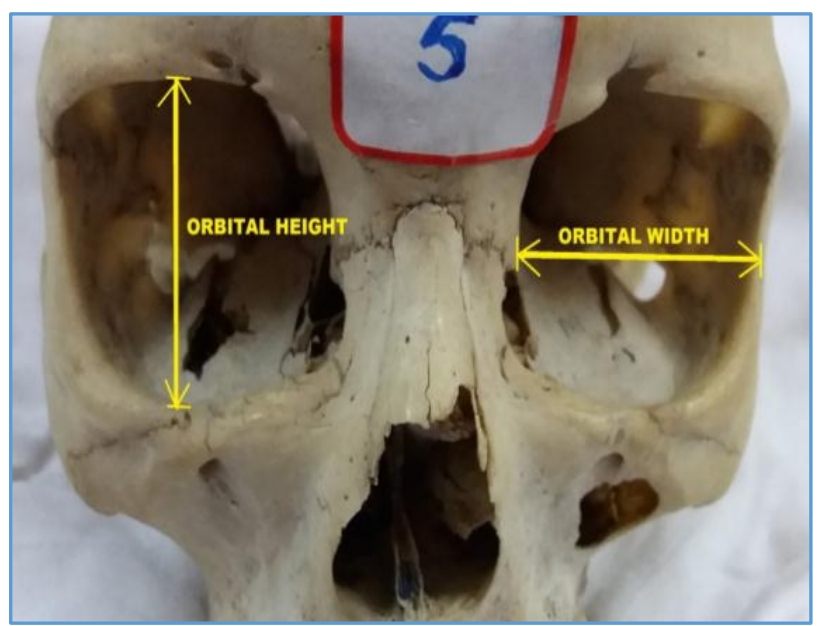

3. Depth of the cavity from all four margins:

a. Superior: Distance between superior margin of the optic canal and superior-orbital notch.

b. Inferior: Distance between the inferior margin of the optic canal and the inferior orbital margin (just above infraorbital foramen).

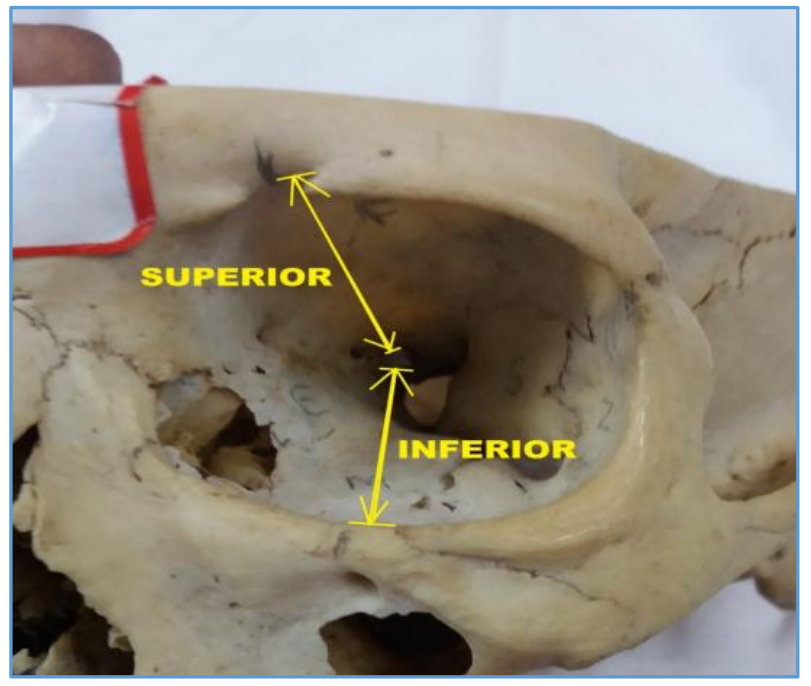

c. Medial: Distance between the medial margin of the optic canal and the anterior lacrimal crest.

d. Lateral: Distance between the lateral margin of the optic canal and the zygomaticofrontal suture.

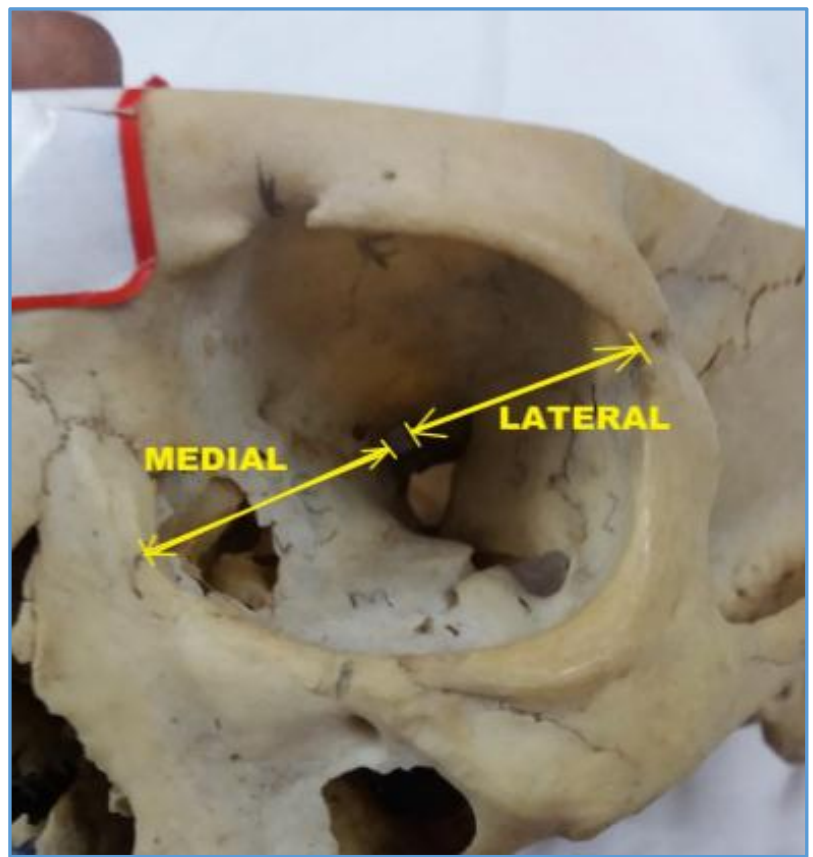

4. Orbital index (OI) was calculated as-

OI= (Orbital Height/ Orbital Width) $\times 100$

5. Safe distance to the optic nerve from each orbital margin was obtained by subtracting $5 \mathrm{~mm}$ from the shortest measured distance on both sides of the skull.

The above observations were analysed using paired ttest ( $p<0.05$ was considered to be significant). The statistical software used was IBM SPSS version 20.0

\section{RESULTS}

1. Mean orbital height was $33.09 \pm 1.89 \mathrm{~mm}$ on the right and $33.03 \pm 1.94 \mathrm{~mm}$ on the left.

2. Mean orbital width was $41.25 \pm 2.65 \mathrm{~mm}$ on the right and $41.11 \pm 2.76 \mathrm{~mm}$ on the left. 
3. Mean orbital index was $80.40 \pm 4.97 \mathrm{~mm}$ on the right and $79.48 \pm 4.97 \mathrm{~mm}$ on the left. The difference in the mean orbital index on right and left $=0.9 \pm 11.11 \mathrm{~mm}$ (Mean \pm SD).

4. Mean distances from the optic canal to the superior, inferior, medial and lateral margins were $50.02 \pm 4.44$, $51.53 \pm 3.13,47.70 \pm 3.31$ and $48.62 \pm 3.32 \mathrm{~mm}$ respectively on the right side. On the left side were 49.00 $\pm 4.37,50.58 \pm 3.18,46.68 \pm 3.44$ and $48.35 \pm 3.25 \mathrm{~mm}$ respectively. Significant difference (p value 0.01 ) exists in the mean distances on right and left sides from all the margins except from the lateral margin as shown in Table 1.

5. On classifying the skulls according to the Orbital Index (OI), $67.7 \%$ were microseme (OI $\leq 83), 29 \%$ were mesoseme (OI $83-89$ ), 3.2\% were megaseme (OI > 89).

6. Safe distance to the optic nerve obtained from superior, inferior, medial and lateral margins on the right side were 26.12, 39.91, 34.96 and $36.98 \mathrm{~mm}$ respectively. Whereas on the left side the safe distance from the superior, inferior, medial and lateral orbital margin obtained were 26.13, 38.19, 33.62 and $38.11 \mathrm{~mm}$ respectively.

\section{DISCUSSION}

A thorough knowledge of the orbit and the important structures in its vicinity such as the optic nerve is vital to surgeons while performing various craniofacial procedures. This study aimed at obtaining a clear understanding of the same.

Although, there are many foreign studies done previously, this is one among the few studies done so far on skulls procured from Southern part of India. Hence, this study has played an important role in opening a new window of knowledge about the orbital morphometry and the associated parameters.

\begin{tabular}{|c|c|c|c|}
\hline Orbital Margin & $\begin{array}{c}\text { Right (mm) } \\
\text { (Mean } \underline{\underline{ \pm}} \text { SD) }\end{array}$ & $\begin{array}{c}\text { Left }(\mathbf{m m}) \\
\text { (Mean } \underline{\underline{S} \text { SD) }}\end{array}$ & $\begin{array}{c}\text { Right-Left } \\
\text { P value }\end{array}$ \\
\hline Superior margin & $50.02 \pm 4.44$ & $49.00 \pm 4.37$ & 0.01 \\
\hline Inferior margin & $51.53 \pm 3.13$ & $50.58 \pm 3.18$ & 0.01 \\
\hline Medial margin & $47.70 \pm 3.31$ & $46.68 \pm 3.44$ & 0.01 \\
\hline Lateral margin & $48.62 \pm 3.32$ & $48 \pm 3.25$ & 0.34 \\
\hline \multicolumn{4}{|c|}{ Table 1 } \\
\hline
\end{tabular}

The mean values of the orbital height and width on the right and left sides in the present study were more or less consistent with that of the other Indian studies,[2],[3] but higher than that of a Nigerian study.[4]

\begin{tabular}{|c|c|c|c|c|c|c|}
\hline Author & $\begin{array}{l}\text { Mean } \\
\text { Right } \\
\text { Height } \\
(\mathrm{mm})\end{array}$ & $\begin{array}{c}\text { Mean } \\
\text { Left } \\
\text { Height } \\
(\mathrm{mm})\end{array}$ & \begin{tabular}{|l|} 
Mean \\
Right \\
Width \\
$(\mathbf{m m})$ \\
\end{tabular} & $\begin{array}{c}\text { Mean } \\
\text { Left } \\
\text { Width } \\
(\mathrm{mm})\end{array}$ & \begin{tabular}{|c|} 
Mean \\
Right \\
Orbital \\
Index \\
\end{tabular} & \begin{tabular}{|c|} 
Mean \\
Left \\
Orbital \\
Index \\
\end{tabular} \\
\hline $\begin{array}{c}\text { Mekala et al } \\
\text { (Indian) }\end{array}$ & 35.5 & 35.3 & 41.7 & 41.8 & 85.22 & 84.4 \\
\hline $\begin{array}{c}\text { Dr.Gopalakrishnan } \\
\text { et al (Indian) }\end{array}$ & 32.75 & 33.05 & 40.62 & 40.75 & 80.69 & 81.16 \\
\hline \begin{tabular}{|c|}
$\begin{array}{c}\text { Jaswinder Kaur } \\
\text { (Indian) }\end{array}$ \\
\end{tabular} & 31.9 & 32.2 & 39.7 & 38.8 & 80.3 & 82.98 \\
\hline $\begin{array}{l}\text { Ukoha et al } \\
\text { (Nigerian) }\end{array}$ & 31.9 & 31.4 & 36 & 34.98 & 88.61 & 89.76 \\
\hline Present Study & 33.09 & 33.03 & 41.25 & 41.11 & 80.4 & 79.48 \\
\hline \multicolumn{7}{|c|}{ Table 2} \\
\hline
\end{tabular}

\begin{tabular}{|c|c|c|c|c|c|c|c|c|}
\hline Author & RS & LS & RI & LI & RM & LM & RL & LL \\
\hline $\begin{array}{c}\text { Huanmanop } \\
\text { (Thai) }\end{array}$ & 44.5 & 44.8 & 46.5 & 45.9 & 42.3 & 42.1 & 46.6 & 47.2 \\
\hline $\begin{array}{c}\text { Munguti et al } \\
\text { (African) }\end{array}$ & 52.9 & 54.40 & - & - & - & - \\
\hline $\begin{array}{c}\text { Karakas et al } \\
\text { (Caucasian) }\end{array}$ & 45.3 & - & 41.7 & \multicolumn{2}{|c|}{44.9} \\
\hline $\begin{array}{c}\text { Hwang } \\
\text { et al (Korean) }\end{array}$ & 44.9 & 45.5 & \multicolumn{2}{|c|}{40.5} & \multicolumn{2}{|c|}{47.4} \\
\hline Present Study & 50.02 & 49 & 51.53 & 50.58 & 47.7 & 46.68 & 48.62 & 48.35 \\
\hline
\end{tabular}

Table 3. The Mean Values of the distance from the Optic Canal to the Orbital Margin being compared to the other Foreign Studies

The mean values of the distance from the orbital margin to the optic canal obtained in the present study were higher than that obtained in a previous Indian study[5] by Shilpa et al.

\begin{tabular}{|c|c|c|c|c|c|c|c|c|}
\hline & & & & & & M & $\mathbf{L}$ & \\
\hline & 5 & & & & & & & \\
\hline & 50.02 & 49 & 51.53 & 50.58 & 47.7 & 46.68 & 48.62 & 48.35 \\
\hline \multicolumn{9}{|c|}{$\begin{array}{c}\text { Table 4. The Mean Values of the distance from the Optic } \\
\text { Canal to the Orbital Margin being compared to an Indian } \\
\text { Study (all values in } \mathrm{mm} \text { ) }\end{array}$} \\
\hline
\end{tabular}

Our results were higher than that obtained by studies done on Thai,[6] Caucasian[7] and Korean ${ }^{[8]}$ population, but lesser than that obtained in a study done on African population. ${ }^{[9]}$

The skulls were further classified on the basis of the orbital index obtained into megaseme, mesoseme and microseme types. $67.7 \%$ of the skulls belonged to the microseme category (orbital index $\leq 83$ ). It was seen that two other Indian studies[2][3] and a Nigerian study[10] also obtained the same result.

\begin{tabular}{|c|c|c|c|}
\hline Authors & Population & $\begin{array}{c}\text { Mean Orbital } \\
\text { Index }\end{array}$ & Category \\
\hline Igbigbi et al & Malawian & 95.19 & Megaseme \\
\hline $\begin{array}{c}\text { Leko Bankole J } \\
\text { et al }\end{array}$ & Nigerian & 104.29 & Megaseme \\
\hline Fathy A et al & Egyptian & 83.75 & Mesoseme \\
\hline Ebeye OA et al & Nigerian & 80.25 & Microseme \\
\hline Jaswinder Kaur & Indian & 81.65 & Microseme \\
\hline Mekala et al & Indian & 85.8 & Mesoseme \\
\hline Present Study & Indian & 79.94 & Microseme \\
\hline
\end{tabular}

Table 5. Comparison of Orbital Index with Previous Studies

The safe distance to the optic nerve from the orbital margins were obtained by reducing $5 \mathrm{~mm}$ from the shortest measured distance from the margins to the optic canal on right and left sides.

\begin{tabular}{|c|c|c|}
\hline Orbital Margin & Right Side (mm) & Left Side (mm) \\
\hline \multirow{2}{*}{ Superior } & $\begin{array}{c}(31.12-5 \mathrm{~mm}) \\
26.12\end{array}$ & 26.13 \\
\hline Inferior & 39.91 & 38.19 \\
\hline Medial & 34.96 & 33.62 \\
\hline Lateral & 36.98 & 38.11 \\
\hline \multicolumn{3}{|c|}{ Table 6 } \\
\hline
\end{tabular}

The knowledge of these values is vital in the evaluation, diagnosis, pre-operative and per-operative planning of 
management for craniofacial syndromes, post-traumatic facial deformities and in the treatment of orbital abnormalities to produce the best aesthetic and functional result. [2] It is also of relevance to anaesthetists in ocular surgeries, while various nerve blocks are being employed.

Injection at the orbital apex which was advocated in the distant past and is now outmoded, has the potential of frank optic nerve injury.[11]

As quoted by Kumar et al, risk factors for optic nerve injury include patients with small orbits, placement of a long needle into the apex and the patient looking up and in at the time of the block during the classical retrobulbar block.[12]

Katsev et al measured the distance from the inferior lateral orbital rim (the traditional insertion point of most sharp needle techniques) to the optic foramen in 120 cadaver orbits and found that in about $20 \%$ of the skulls this distance was $45 \mathrm{~mm}$ or less. They postulated that a $38 \mathrm{~mm}$ needle could injure the optic nerve, while it was encased in the relatively immobile annulus of Zinn in an orbit less than 45 $\mathrm{mm}$. They recommended using shorter needles such as 31 $\mathrm{mm}$ or less to eliminate this possibility.[13]

Pautler et al reported that when the patient is asked to look up and in, this brings the medially positioned optic nerve more lateral and closer to the needle tip.[14]

\section{CONCLUSION}

The knowledge of these values is vital in the evaluation, diagnosis, pre-operative and per-operative planning of management for craniofacial syndromes, post-traumatic facial deformities and in the treatment of orbital abnormalities to produce the best aesthetic and functional result. It is also of relevance to anaesthetists in ocular surgeries, while various nerve blocks are being employed.

\section{REFERENCES}

[1] Standring S. The orbit and the accessory visual apparatus. Gray's anatomy: the anatomical basis of clinical practice. $40^{\text {th }}$ edn. London, UK: Churchill Livingstone 2008: p. 655-66.

[2] Mekala D, Shubha R, Devi RM. Orbital dimensions and orbital index: a measurement study on south Indian dry skulls. Int J Anat \& Res 2015;3(3):1387-91.
[3] Gopalakrishna K, Kashinatha M. The craniometrical study of orbital base of Indian population and its applied importance. Sch Acad J Biosci 2015;3(2):61823.

[4] Ukoha U, Egwu OA, Okafor IJ, et al. Orbital dimensions of adult male Nigerians: a direct measurement study using dry skulls. Int J Biol Med Res 2011;2(3):688-90.

[5] Gosavi SN, Jadhav SD, Zambare BR. Orbital morphology with reference to bony landmarks. Rev Arg de Anat Clin 2014;6(1):20-5.

[6] Huanmanop T, Agthong S, Chentanez V. Surgical anatomy of fissures and foramina in the orbits of Thai adults. J Med Asso Thai 2007;90(11):2383-91.

[7] Karakas P, Bozkir MG, Oguz O. Morphometric measurements from various reference points in the orbit of male Caucasians. Surg Radiol Anat 2003;24(6):358-62.

[8] Hwang K, Baik SH. Surgical anatomy of the orbit of Korean adults. J Craniofac Surg 1999;10(2):129-34.

[9] Munguti J, Mandela P, Butt F. Referencing orbital measures for surgical and cosmetic procedures. Ant J of Africa 2012;1(1):40-5.

[10] Ebeye OA, Otikpo O. Orbital Index in Urhobos of Nigeria. IOSR Journal of Dental and Medical Sciences 2013;8(2)51-3.

[11] Hamilton RC, Gimbel HV, Strunin L. Regional anaesthesia for 12,000 cataract extraction and intraocular lens implantation procedures. Can J Anaesth 1988;35(6):615-23.

[12] Kumar CM. Orbital regional anesthesia: complications and their prevention. Indian J Ophthalmol 2006;54(2):77-84.

[13] Katsev DA, Drews RC, Rose BT. An anatomical study of retrobulbar needle path length. Ophthalmology 1989;96(8):1221-4.

[14] Pautler SE, Grizzard WS, Thompson LN, et al. Blindness from retrobulbar injection into the optic nerve. Ophthalmic Surg 1986;17(6):334-7. 